\title{
An Assessment of Methanotrophs Producing Industrial-Grade Lipids for Biofuels and Other Commercial Chemicals
}

\author{
Alex Zappi ${ }^{1,2}$, Dhan Lord Fortela ${ }^{1,2, *(D)}$ and William E. Holmes ${ }^{1}$ \\ 1 Energy Institute of Louisiana, Lafayette, LA 70503, USA; C00012281@louisiana.edu (A.Z.); \\ william.holmes@louisiana.edu (W.E.H.) \\ 2 Department of Chemical Engineering, University of Louisiana Lafayette, Lafayette, LA 70503, USA \\ * Correspondence: dhan.fortela@louisiana.edu
}

Received: 12 June 2020; Accepted: 28 July 2020; Published: 30 July 2020

\begin{abstract}
With an ever-increasing release of harmful greenhouse gases into the environment, there is an ongoing search for a renewable source of energy to replace the current means of producing energy. One promising source is from methanotrophic bacteria, which uses methane as its primary carbon source to produce valuable byproducts including lipids. These lipids could be used in the production of biofuels and other important industrial chemicals including plastics and surfactants. The use of methanotrophs would lower the amount of methane in the atmosphere from two sides, in the growth and cultivation of methanotrophs and in the replacement of conventional fossil fuels. The development of such a system requires a good understanding of the bacteria responsible and the steps of growth/culturing and extraction. An integrated system that uses every product of methanotrophic growth could impact multiple markets and help make this technique economically feasible as well as provide the groundwork for more sustainable engineering practices. Integration of this technology into an industrial setting would help spread the scope of this technique, and by using innovative sources of methane (landfills and locations of high organic decomposition), the extent of environmental benefits can expand even further. This technology allows for a more environmentally friendly alternative for fuels in both its production and utilization.
\end{abstract}

Keywords: methanotrophs; lipids; biofuels; lipids production

\section{Introduction}

With the increasing need for alternative fuel sources, the potential of lipids as an industrial feedstock is becoming more promising. Lipids produced from methanotroph growth have the potential to be used in biofuels and other products, and the protein of the subsequent delipified biomass has potential in many industries as well. The development of industrial uses of methanotrophs for lipids focus on optimizing two major steps: growth/culturing and extraction. Methanotrophs are normally grown in aerobic conditions with access to a methane gas source [1]. Though the exact species of methanotroph used will determine many of the growth considerations, a feedstock source has to contain important fundamental compounds for cultivation; many methanotrophs require the presence of copper to fully utilize its biomass producing-enzymes [2]. Extraction and separation of lipids is usually performed in a two-step method to lyse the cell structures to release lipids followed by a process of separation using the difference of polarities of cell structures [3]. After the lipids are extracted, further use of the delipified biomass can also be used as a source of other products (such as proteins). Figure 1 outlines this process. 


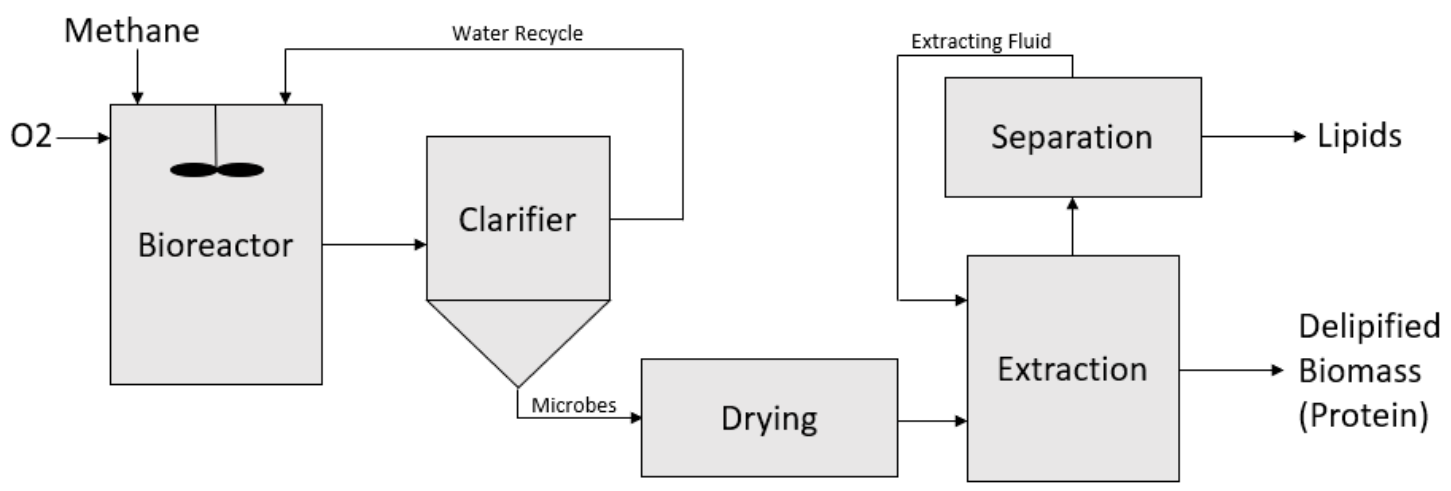

Figure 1. General Processing Method of Producing Lipids and Protein from Methanotrophs.

\section{Lipids}

Lipids are a class of hydrophobic and amphiphilic macromolecules made of chains of hydrogen and carbon that are insoluble in water and soluble in organic solvents. In cells, they are used as means of energy storage as well as chemical communication and can be found in almost all living organisms; moreover, cells use lipids for the main material for their membranes [4]. Lipids are normally collected from plant-based and animal-based sources (primarily soybeans, but rapeseed, sunflower seeds, lard, and tallow also hold strong positions in the lipid market) [5-10]. One of the most promising industrial uses of lipids has been in the fuel industry as an alternative to fossil fuels. This would lower the dependence on the limited amount of fossil fuels in existence and provide a more environmentally friendly option. One of the major uses for lipids as an alternative fuel source is biodiesel. This use of biodiesels is much safer than using normal diesel in the fact that it is biodegradable and nontoxic [11,12]; however, the current prices of biodiesel still make this alternative unfavorable. Recent research suggests that these prices may soon reach a competitive level, as the current cost of biodiesel is around $\$ 3.10$ per gallon while normal diesel is around $\$ 3.00$ per gallon $[13,14]$. Though biodiesel is a possible renewable fuel source, there has been much research recently on a new branch of fuels called green diesel (also referred to as renewable diesel). Green diesel is fuel produced from oils and fats, but unlike biodiesel, it can be produced in preexisting petroleum refineries, a major advantage for the integration of renewable techniques into widely used systems [15].

Though this analysis is more focused on lipid use for biofuels, lipids have a place in a large array of products. One industrial use for lipids is as a surfactant [16]. However, the use of lipids span into many different industries as well. They are used in cosmetics, medicine, soaps, and many different industries. The surfactants industry is enormous and is constantly expanding. In a report by Grand View Research (2015), the global demand for surfactants was 15,641.7 kilotons in 2014 and, between the years of 2015 to 2022, this is expected to expand at a compound annual growth rate (CAGR) of $4.3 \%$ [17]. The drive for such expansion is the relative eco-friendliness of the surfactant market along with the ever-present need for industrial surfactants. Lipids have recently found potential in the plastics industry as a more renewable and degradable source. Plastics represent a very large industry with $225 \mathrm{mt}$ produced per year and are used in a large portion of commercial goods [18]. In a report by the UN, it is estimated that more than 8.4 billion tons of plastics have been produced since 1950, and $60 \%$ of that has ended up in a landfill or in an ocean. Most plastics are produced using fossil fuels, mainly ethylene, butene, and propylene as the basis for long polymers; however, this use leads to plastics that are difficult to be naturally broken down. Analyses show that an abundance of plastics can be found in nature as pollution in waterways and runoffs from landfills, which requires innovative solutions for remediation, but prevention is also possible by using lipid-based plastics (bioplastics) as a more degradable option. 


\section{Methanotrophic Bacteria}

Methanotrophs are a type of microorganism that use methane as their main carbon and energy source and degrade it into potentially useful compounds. These bacteria and archaea are a part of a larger group called methyltrophs that utilize reduced carbon in methyl compounds that contain no carbon-carbon bonds. Methyltrophic bacteria include bacteria that can source carbon from a large variety of compounds including methanol, methylated amines, halomethanes, and methane, and these types of bacteria play a major role in the natural carbon cycle and help to reduce the concentration of dangerous greenhouse gasses in the atmosphere, most notably methane) $[19,20]$. As the only biological sink for methane and a source for useful biproducts, methanogens have received much focus over the past 50 years.

Methanotrophs were discovered in 1906 by Sohngen, a Dutch microbiologist, and for the next 60 years very little research was directed towards these types of bacteria; however, in 1970, Whittenbury identified about 100 different types of methanotrophs and was able to classify them based on their physiology and carbon utilization pathways [21]. Shortly after, Hanson et al. identified methanotrophic yeasts, further supporting the fact that methanotrophic bacteria are naturally common, and these discoveries led to the modern utilization of their ability to break down methane [22]. Methanotrophic bacteria have begun to be used in the field of Environmental Engineering to breakdown pollutants and manage the release of methane into the atmosphere. Their unique properties have been used in coal mines and landfills for gas removal and toxic remediation [23].

\subsection{Biological Processes}

Methanotrophic bacteria are usually classified into two major groups: Type I and Type II; each prefer different environmental conditions and process methane in different ways. Type I methanotrophs are Gammaproteobacteria and prefer lower concentrations of methane and high levels of copper and nitrogen, which are mostly psychrophiles and mesophiles [21,24]. Type I methanotrophs utilize the ribulose monophosphate pathway for formaldehyde assimilation resulting in one ATP for every three formaldehyde molecules [19]. It was found in copper-deficit conditions, cells were devoid of intracytoplasmic membranes with vesicles only on the edges of cells [19]. Type II methanotrophic bacteria are Alphaproteobacteria and prefer higher levels of methane and lower levels of dissolved oxygen. These methanotrophs utilize the serine pathway which use carbon dioxide and formaldehyde to produce two NADH and two ATP for each molecule of acetyl-CoA [24]. Though these two main types hold true for a majority of methanotrophs, there have been recent discoveries of much more exotic types, including methanotrophic bacteria that can utilize multicarbon compounds and some that can exist in extreme temperatures and $\mathrm{pH}$ levels [21]. One type of nominal importance is referred to as type $X$; this form is similar to the two other forms in particular ways. It has the chemical composition of Type I with the utilization of the serine pathway found in Type II. It has the capability to survive in extremely high temperatures, and it is best suited in cases where the temperature is too high for the other types [25]. Figure 2 shows the process that methanotrophic bacteria breakdown methane into carbon dioxide with a split determined by the type (only Type I and Type II are illustrated, but type X and those methanotrophs similar to type $\mathrm{X}$ would follow a pathway similar to Type II, which includes the serine pathway) $[19,20,26]$. 


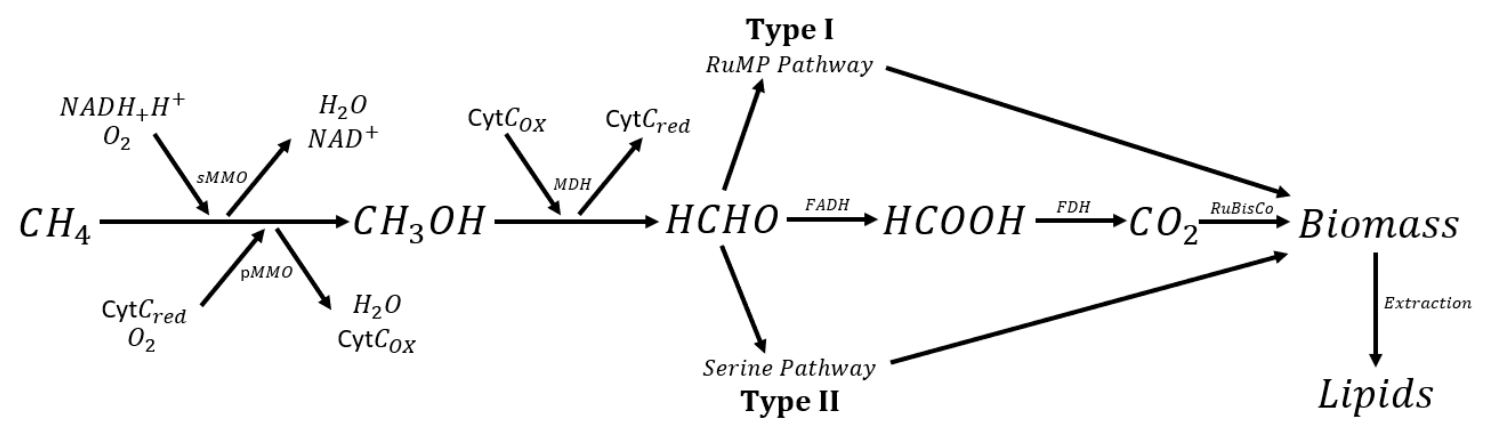

Figure 2. Process Used by Methanotrophic Bacteria for the Conversion of Methane into Biomass (Hanson and Hanson, 1996).

The first step in this chemical process is the conversion of methane to methanol, which is achieved through the utilization of two forms of methane monooxygenase (MMO). These enzymes are divided into three specific types membrane-bound particulate MMO (pMMO), ammonia monooxygenase (AMO), and the soluble MMO (sMMO) [27]. Methanotrophs use either sMMO or pMMO depending on the conditions of the process, mainly determined by the concentration of copper ions in the environment; if there is sufficient copper available, methanotrophs utilize $\mathrm{pMMO}$, while sMMO is used in lower ratios of copper to biomass $[28,29]$. This differentiation is due to the existence of an active copper site, where sMMO has a nonheme diiron active site and $\mathrm{pMMO}$ has a copper active site [29]. When enough copper is present, the pMMO oxidizes cytochrome c oxidase (CytC), a common enzyme used in the electron transport chain, producing water and an oxidized form of CytC; copper acts as the metallocofactor [30]. If the bacteria are in a state of copper deficiency, sMMO oxidizes nicotinamide adenine dinucleotide (NAD) to its oxidized form NAD+ (water is also produced as a biproduct). Both of these processes also result in the production of ethanol for the next step. The next step involves the conversion of ethanol to formaldehyde. This is accomplished by using methanol dehydrogenase (MDH) as a catalyst [21]. This quinoprotein found in the periplasm of methanotrophs and other methylotrophic proteobacteria into formaldehyde [2]. The third step in the process is dependent on the type of methanotroph. If the bacterium is Type I, it follows the ribulose monophosphate (RuMP) pathway; if it is Type II, it follows the serine pathway [19]. The RuMP pathway (ribulose monophosphate pathway) uses one ATP for every molecule of formaldehyde to form glyceraldehyde-3-phosphate, used for biosynthesis [24]. The serine pathway uses two ATP and two NADH to form one molecule of acetyl-CoA from formaldehyde and carbon dioxide; the resulting acetyl-CoA is further processed for biosynthesis [24]. It is important to note that both of these pathways, though unique, result in useful biomass.

Some of the formaldehyde is also converted into formic acid through the utilization of FADH; the formic acid is then converted to $\mathrm{CO}_{2}$ using the enzyme formate dyhydrogenase (FDH). The $\mathrm{CO}_{2}$ is then used by the bacteria through the enzyme ribulose-1,5-bisphosphate carboxylase/oxygenase (RubisCO) [31]. RubisCO is an enzyme found in most plants in the process of photosynthesis; it is the first major step in carbon fixation, which ultimately leads to the production of useful materials, usually glucose. In the case of methanotrophs, it is used later in the process to convert the resulting $\mathrm{CO}_{2}$ from previous steps into a more energy-useful form.

Methane is released into the atmosphere from a large variety of sources, both natural and industrial. In 2012, California quantified these sources as oil and gas (9\%), wastes (25\%), and agriculture (62\%) which includes manure, enteric fermentation, and rice [32]. This widespread and continuous release led to dangerous levels of methane in the atmosphere contributing to over $10 \%$ of greenhouse gasses released with over $580 \mathrm{Tg}$ in annual emissions; the only natural biological sink for methane are methanotrophs $[20,33]$. Methanotrophs serve an important role in the reduction of methane in the atmosphere, waterways, and soils and help to naturally limit dangerous levels of methane. 


\subsection{Other Uses of Methanotrophic Bacteria}

The use of methanotrophic bacteria for lipid production can be expanded and integrated with other processes; for that reason, it is important to understand some of their other uses. Methanotrophs are special in their ability to naturally decompose methane, a unique property associated with the methane monooxygenases enzymes (MMO). MMO has been used, not only for the degradation of methane, but for the bioremediation of toxic chemicals that contain a high variety of heavy metals, petroleum hydrocarbons, lindane, trichloroethylene, and other common substrates, including toluene, styrene, and halogenated benzenes [34,35]. The use of methanotrophic bacteria for such remediation situations is encouraged by the fact that only methane and oxygen has to be supplied. Specific methanotrophs containing each form of MMO (pMMO and sMMO) are preferred on a case-by-case basis. Most research has shown sMMO has the ability to degrade compounds more quickly, which made it the focus of much early work; however, more recent work shows that pMMO has the ability to survive in more extreme conditions and in the presence of more compounds [36]. The use of type $\mathrm{X}$ methanotrophs have not been fully researched but are notable in cases of extreme temperatures. However, the main issues associated with the use of methanotrophs for remediation are competitive inhibition of $\mathrm{MMO}$, gas transfer limitation, lack of suitable methanotrophic isolate, regeneration of reducing equivalents, and product toxicity as noted by Jiang et al. [23].

Not only are methanotrophic bacteria used to degrade toxic chemicals, they are used in a more direct way to mitigate the release of harmful methane into the environment. They can be found naturally in many high methane environments, including wetlands and bogs where the decomposition of plant and animal matter occurs in abundance and are a major factor in the control of atmospheric methane. Recent engineering work has focused on the utilization of methanotrophs in manmade sources of methane; this focus has primarily been set on landfills where methane is produced in large amounts. The United State Environmental Protection Agency (EPA) has reported that 50\% of landfill gas (LFG) is methane and that methane is 28 to 36 more impactful than $\mathrm{CO} 2$ at trapping heat in the atmosphere [37]. The EPA also reported that municipal solid waste (MSW) landfills are the third largest source of human-related methane released in the United States. This large release of methane has led to the creation of techniques of using methanotrophs in these sites. The most common of these techniques use "biocovers" containing methanotrophs to cover landfill sites and lower the amount of methane that leaves the landfill [25]. Research performed by Cebron et al. in 2007 has shown that both Type I and Type II thrive in this kind of environment with the Type II methanotrophs relating to the genera Methylocella-Methylocapa and the Type I methanotrophs relating to Methylobacter and Methylomonas [38].

\subsection{Species of Methanotrophs}

There is a wide array of types of methanotrophs, each with their own set of benefits based on the conditions needed of them. One common Type I methanotrophic bacteria used for analysis is Methylomicrobium buryatense 5GB1; this methanotroph is prevalent in research due to its high resistance to contamination and deviation in $\mathrm{pH}$ levels $[1,26,39]$. This bacterial species is common in natural environments such as in soda lakes where it can sustain fluctuations in temperatures, $\mathrm{pH}$, and salinity [40]. Because of its abundance in nature, it is easily obtained. Another advantage of this type of methanotroph is its ability to thrive in low concentrations of methane and oxygen; though aerobic, the ability to reduce the oxygen requirements further expands its potential in industry [1].

One example of a Type X methanotroph is Methylococcus capsulates, which is studied extensively due to its affluence in natural methane leaks. This type of bacteria thrives in environments of high copper concentrations (Karlsen et al.) [41]. This methanotroph is also thermophilic, meaning it can survive at relatively large temperatures, which can help its use at high temperatures and in situations where high temperatures are not optional [42].

Another large group of methanotrophs are the methanotrophic archaea. This type methanotroph, just like its bacterial counterpart, plays an important role in the conversion of methane and often 
pairs with sulfate-reducing bacteria in anaerobic conditions [43]. One important form of these archaea is called the anaerobic methane-oxidizing archaea (ANME). There are three main groups of these microorganisms: ANME-1, ANME-2, and ANME-3 [44]. ANME-1 are related to Methanosarcinales and Methanomicrbiales while ANME-2 are related to cultivated members of the Methanosarcinales [45]. ANME-3 are a newer group of archaea more recently identified as a separate group but are still distinct based on an analysis of their $16 \mathrm{~S}$ rRNA genes; this group is related to Methanococcoides [44,46]. Methanotrophic archaea tend to prefer marine environments; in fact, they were first found in abundance in sediments of cold seeps and are also found in methane-sulfate transition zones of many coastal environments [46]. This type of microorganism, like most methanotrophs, show higher activity at higher methane partial pressures. In the case of ANME-2, $10 \mathrm{MPa}$ is optimum for in vitro incubations [44]. These types of methanotrophs are important for environmental diversity; however, currently, there are few major industrial uses for ANME, making more research required for an accurate assessment of their sustainable applications to industry.

These are just two of many species of methanotrophs; however, there are many more types that can be used in a variety of situations. In a report by Fradet et al., a few of the major genera are listed: Methyloferula, Methylohalobius, Methylomarinovum, Methylogaea, Methylomagnum, Methylparacoccus, Methyloglobulus, Methylosoma, Methylomarinum, Methylosphaera, and Methyloprofundus [47]. In a review of prominent research in this area, there are some species that tend to be preferred for analysis: M. buryatense 5GB1, Methylomonas methanica, Methylosinus sporium, Methylocella silvestris BL2, Methylocapsa acidiphilia, Methylococcus capsulatus, Methylosinus trichosporium OB3b, and Methylocystis parvus OBBP $[19,21,48,49]$.

\subsection{Sources of Methanotrophs}

In analyzing the scope and prevalence of methanotrophs naturally, it is necessary to understand the natural environment of these microorganisms. They can be found in common locations (within the topsoil) to deep within the oceans in hydrothermal vents; these large-scoping conditions show the versatility of methanotrophs and the important role they play in environmental processes [50,51].

Naturally occurring methanotrophic bacteria are most often found within the first few millimeters below the sediment surface where there is an interaction between the oxygen found in the atmosphere/water and methane from below the surface [50]. This balance between gasses creates the optimum levels of methane and oxygen with the exact depth determined by the preference of the bacteria in question (Type I and Type II). Though there is an abundance of research on the ideal cultivation conditions, there is little focus on the concentration of methanotrophs in naturally occurring soils; however, in an analysis by Kolb et al., the concentration by type of methanotroph was explored in detail from samples from rice fields. Their results show that the total amount of methanotrophs present is around $0.9 \times 10^{6}$ molecules per gram of soil in this case [52]. This amount can vary, however, depending on the location the sample was collected. A rice field contains a high amount of decomposing matter, which would lead to a high concentration of methanotrophic bacteria; however, a swamp, for example, would contain even more since the concentration of living, and therefore dying, organic matter is higher. Trends show that methanotrophs exist in any location that has easy access to methane, oxygen, and required nutrients $[20,21]$.

Methanotrophic bacteria are also found in extreme conditions, such as hydrothermal vents and other natural gas seeps, where methane is released in abundance but access to these are very limited [51]. Very little is known about the exact type of methanotrophs that exist in these conditions. However, the research that has occurred on these types of methanotrophs indicate a gene that is responsible for allowing these bacteria to survive in oxygen-limiting conditions [53]. These hydrothermal vents have also shown the existence of anaerobic methanotrophs that require no oxygen to process methane; these forms of methanotrophs also have the ability to survive at extraordinarily high temperatures [54]. Though the cultivation of methanotrophs at these conditions and locations are extremely difficult, these sites offer a unique look at more exotic uses and forms of methanotrophs. 
There is also evidence to suggest that methanotrophic bacteria are present at the sites of permafrost thaw environments; these locations include frozen ground from nearly one million years ago and is responsible for containing almost half of the world's soil carbon [55]. These locations tend to have Type I methanotrophs as the primary form and had a strong preference to areas with high levels of phosphorus, conductivity, and suspended solids [56]. They also support the assumption that methanotrophs can exist in locations of low oxygen content. These also show that methanotrophs play an important role as natural methane sinks.

\section{Cultivation Methods for Methanotrophic Bacteria}

The cultivation methods for growing methanotrophs vary greatly on their future use; for small scale analysis and sampling sizes, small cultures can be grown in a variety of mediums that allow for the micromanagement of key growth conditions and close observations. However, larger scales (normally larger than one liter) require continuous systems for an accurate uniformity of conditions, usually caused by a change in the concentration of methane during the growth of the methanotrophic bacteria. It is also important to consider the exact type of methanotroph used for culturing. As with most bacteria, variations in the optimal growing conditions on a basis of physiological requirements lead to many cultivation methods being required based on the type [57]. Some extreme forms of methanotrophs may require extreme temperatures or acidities, for example. The following section serves to outline general cultivation and growth techniques with supportive technical examples cited; these sections serve as an analyses of pre-existing cultivation processes for possible integration into lipid-focused industrial processes using methanotrophs.

When culturing methanotrophs in nearly any condition, it is important to have a growth medium with a supply of nutrients to support basic bacterial function. Early research performed by Whittenbury et al. in 1970 has served as the basis for the general composition of this medium for a large majority of modern research $[2,58,59]$; they defined this mixture as percentage of distilled water $(\%, w / v)$ : $0.1 \mathrm{MgSO}_{4}{ }^{*} 7 \mathrm{H}_{2} \mathrm{O}, 0.02 \mathrm{CaCl}_{2}, 0.0004$ Sequestrene Iron Complex, $0.05 \mathrm{NH}_{4} \mathrm{Cl}, 1.25$ Agar (if using plates), and $0.05(\% v / v)$ Trace Element Solution. An important component of the trace element solution is copper (usually as $\mathrm{CuSO}_{4}$ ); most sources utilize a copper concentration of around 1-5 $\mu \mathrm{M}[49,59,60]$. A review of literature revealed that the trace element solution contains a variation normally containing the following compounds: $\mathrm{FeSO}_{4}, \mathrm{ZnSO}_{4}, \mathrm{MnCl}_{2}, \mathrm{CoCl}_{2}, \mathrm{NiCl}_{2}, \mathrm{NH}_{4} \mathrm{Cl}, \mathrm{H}_{3} \mathrm{BO}_{3}$, and EDTA (ethylenediaminetetraacetic acid) [48,49,57-59]. This complexity shows that an industrial transition would require an intensive conversion process, making these techniques difficult; a premixing process would be required to create the adequate growth media that causes a large array of issues. Costs would also be greatly increased, as some of these chemicals are costly leading to more difficulties [61,62].

Other than the growth medium, the other most important factor is the biogas supply. Most methanotrophic bacteria mainly need oxygen and methane from the gas supply. Research performed by Tays et al. in 2018 indicated the optimum levels of methane to be $0.5-2.5 \mathrm{mmol}$ of every $100 \mathrm{~mL}$ of cultures used [59]. When the levels of methane were less than $0.5 \mathrm{mmol}$, the bacteria became methane limited; at levels greater than 2.5, they became oxygen limited. Other than these essential parameters, there is little notable significance on the source and composition of the biogas. However, one important aspect of culturing methanotrophs is ensuring they have adequate exposure to methane, which is often limited in its solubility. Methane has a solubility in water of $22 \mathrm{mg} / \mathrm{L}$ ( 25 degrees Celsius) [63]. This could cause a system involving a gas/liquid interface between methane and natural gasses to be inhibited by methane's solubility and should be carefully considered in bioreactor designs and operating pressures. An increase in operating pressure would aid in the absorption of methane into the bacterial slurry.

In selection of the gas source, a comparison of their methane composition is necessary. The easiest gas to access for use on methanotrophs is natural gas. Natural gas has a molar composition of around $94.7 \%$ methane, $4.2 \%$ ethane, $0.2 \%$ propane, $0.04 \%$ butane, $0.02 \%$ pentane, and some other trace components [64]. A source like this would allow enough methane for bacterial growth, but in 
most cases, it is best to add an extra oxygen source as most methanotrophs are aerobic $[1,65]$. Current natural gas prices are shown to be around $\$ 6.23$ per 1000 cubic feet [66], which make it a relatively cheap source of methane. Another potential source of methane is from renewable natural gas (RNG), which is natural gas derived from organic waste material. It can be sourced from food waste, landfills, and animal/plant-based material [67]. A major subset of RNG is biomethane, an RNG that has most of the other trace compounds removed resulting in nearly pure methane gas [68]. RNGs offer a unique opportunity to further enhance the sustainability of methanotrophic processes by reducing the amount of methane released straight into the atmosphere by sourcing it as a feedstock for the bacteria; however, at the current time, it may not be economically feasible, as conventional natural gas prices tend to be around $\$ 0.025 / \mathrm{kW} \cdot \mathrm{h}$ cheaper [69].

Depending on the purpose of the cultured methanotrophs, the size of the culturing method will vary. If small scale use is needed, methanotrophs can be cultured in small hermetic microreactors that allow no gasses to escape $[2,49,50,60]$. Larger scale systems may require the use of a continuing flowing system of gasses and nutrients as the methanotroph amount increases [70-72]. Examples of various works reviewed are explored later on showing a wide variety of different examples of reactors and production methods.

\section{Lipids Production and Extraction of Lipids from Methanotrophic Bacteria}

Natural gas is a mixture of carbon containing gasses that can be used as a fuel source, but it is very difficult to store, transport, and use in such a gaseous state [73]. Because of this, much focus in recent years has been attributed to finding a means to easily convert these gasses into a liquid fuel [48]. Microorganisms, including methanotrophic bacteria, can accomplish this by intaking the gas and producing useful byproducts [1]. The lipid-based fuel is much easier to use and offers a more sustainable form of fuel [73]. Methanotrophs can be used to produce these biofuels as a lipid source as well as produce other important byproducts while reducing methane content. The search for an environmentally friendly means of converting natural gas into liquid form has been fueled by the recent decline of natural gas prices, \$13/million BTU in 2008 to \$3/million BTU in 2015 [26].

\subsection{Lipids in Methanotrophs}

Lipids are a part of the biomass produced from the conversion of methane in methanotrophs. Lipids found in the membrane of cells represent the majority of the lipids found in the bacteria which is a common phenomenon of cell growth in the presence of copper with pMMO [26]. Though most lipids used in biofuels are triglycerides, biofuels from methanotrophs use phospholipids, and most fatty acids produced by them are either saturated or monounsaturated with carbon chain length of 14-18 and are suitable for use in biodiesel [74]. The phospholipids produced have two major classes: phosphatidylglycerol (PG) and phosphatidylethanolamine (PE). The form of the lipid produced is determined by the pathway used by the methanotroph. If processes follow the serine pathway (as in most Type II methanotrophs), polyisoprenoid lipids are produced while polymethylenic lipids are produced from the RuMP pathway (as used in most Type I methanotrophs) [75]. The exact lipid concentrations and compositions varies on the exact methanotroph, but as an example, M. buryatense 5GB1 composed of mainly myristic acid, palmitic acid, and mono-unsaturated fatty acids [26].

To extract lipids from bacteria, a successful technique to disrupt cells must be used followed by the separation of lipids from other compounds using a solvent to match its polarity [3]. The selection of a disruption technique and solvent is very important to yield high levels of lipids and must be carefully selected based on the exact nature of the biomass) [48].

\subsection{Microbial Lipid Extraction Techniques}

One of the most common and longest used techniques to extract lipids is the Bligh and Dyer method [76]. This method was developed in 1959 as a more universal and effective technique from the Folch method and still remains prominent today. It involves a two-step extraction process using a 
mixture of methanol, chloroform, and water where the lipids preside in the chloroform phase. The ratios of the mixture vary but are usually around 1:2:0.8 or 2:2:1.8 [76]. There are, however, some downsides to using this method, mainly toxicity and cost. This method requires the use of highly toxic compounds, which make using this technique dangerous and requires a great amount of care and personal protection. Secondly, large scale industrial processes inhibit the use of this process due to high costs [65].

Hexane has also been used as a common solvent for these processes and are often considered in large-scale lipid extractions due to its affordability and ease of use in an industrial setting. Some success has been found in the combination of hexane and methanol in the FAMEs yield (fatty acid methyl esters) [77]. In an analysis by Shin et al., the optimum conditions for this technique are a volumetric proportion of methanol to hexane of 1:1, an extraction time of $120 \mathrm{~min}$, and ratio of solvent volume to dry biomass of $10 \mathrm{~mL} / \mathrm{g}$ [77]. They further concluded that this technique offers a wide degree of scale-up possibilities for use in an industrial setting. However, due to hexane's limited solubility it could exclude important byproducts from the overall yield [65].

Another method of extraction is a supercritical fluid extraction (SFE) system. An SFE system uses $\mathrm{CO}_{2}$ past its critical pressure and temperature as a "solvent," and by modifying the pressure and temperature, a certain compound can be uniquely selected for extraction. The $\mathrm{CO}_{2} /$ compound mixture can be separated once the pair is depressurized [78]. This method is effective and comparable to other methods of extraction; however, the types of lipids extracted vary between techniques [79]. The more polar lipids in methanotrophs would not be fully extracted in these conditions.

Though many extraction techniques exist, these were mentioned for their prevalence, especially in industry, and in order to better demonstrate their benefits and potential downsides, a quick comparison will be done. It is important to note that comparisons are difficult for industrial uses as many factors play into the selection of the optimal method; for that reason, these comparisons will be broad and generalized for an overall idea. In terms of pure extraction bulk, the Bligh and Dyer method seems to be the most solidified and researched method with an extraction percentage of around $30 \%[80,81]$. Though hexane extraction shows great separation as well, it is an expensive process that requires a large amount of time (Shin et al., 2018; Fei et al., 2014). For a more selective process, SFE systems are an option, but much care must be taken for the potential loss of overall lipid yields [79]. In the selection of a preferred extraction technique, many factors should be considered on a case-by-case basis.

\subsection{Lipid Conversion to Biofuels}

One example of a successful extraction technique of methanotrophs for use in biofuels was performed by Dong et al. in the following manner, $50 \mathrm{mg}$ of dry biomass and deionized water were added to a $10 \mathrm{~mL}$ microwave tube and was heated in a microwave reactor (this is a step of pretreatment that aids in the exposure of lipids from bacterial cells) [26]. After this pretreatment step, hexane was added to the solutions, which were placed on a multistirrer plate for one hour. After extraction, the mixture was left to sit for one hour for phase separation (further freezing and centrifugation were applied). The solvent (hexane) was then evaporated at forty degree Celsius. The leftover fatty acid mass was dried. This process is just one example of experimental methods to isolate for biodiesel use [26]. Fei et al. report in a preliminary cost assessment that biofuel from methanotrophs could cost around \$100-\$200 dollars per ton, an encouraging figure [65].

Biodiesel can be obtained from using transesterification to collect a mixture of fatty acid alkyl esters [82]. Transesterification involves the reaction of an alcohol (usually ethanol or methanol) with a glyceride with the use of a catalyst; the catalyst can be a strong acid or base or, at a larger scale, usually sodium or potassium methanolate [83]. In the case of bacteria, $\mathrm{H}_{2} \mathrm{SO}_{4}$ has been shown to have success as the catalyst [84]. The products of transesterification are glycerol and biodiesel.

These processes can be optimized for environmentally beneficial methanotrophs, making them an ideal source for lipids. Methanotrophic bacteria have the ability to mass produce lipids while simultaneously reducing the amount of atmospheric methane, both in its culturing and as a substitute 
for fuels that release large amount of hazardous chemicals. In an analysis performed by Burdette, for every $0.75 \mathrm{mMol}$ of methane consumed, $6 \mathrm{mg} / \mathrm{L}$ of total biomass is produced and $1.3 \mathrm{mg} / \mathrm{L}$ of fatty acid methyl esters (FAME) [48]. By making biomass from methanotrophs the primary source for the preceding processes, the integration of sustainable processes into commonplace industries becomes more possible.

\section{Bioreactor Designs and Case Studies Using Methanotrophs}

One scaled-up method of biofuel production from methanotrophs was explored by Dong et al. in 2017 [26], they fed a solution of fresh biomass slurry (16.6 g), water, and a $\mathrm{NaOH}$ solution $(20 \%$ on a volume basis) into a reactor (Parr Instruments 4560 Mini Stirred Reactor). The resulting combination had $1 \%(w / v)$ of $\mathrm{NaOH}$ and $10 \%$ biomass; the combination was then heated, cooled, and combined with $\mathrm{H}_{2} \mathrm{SO}_{4}$ (to a concentration of $2 \% \mathrm{w} / v$ ). The biomass was then heated again for acidic hydrolysis. Then, hexane was used for extraction during centrifugation. The hexane phase was then evaporated for a collection of lipids for drying. This approach showed success and the possibility for scaling-up to industrial size processes and yielded a free fatty acid (FFA) purity as high as $97 \%$.

Another example of a bioreactor setup was performed by Gilman et al. in 2015 [1]; they used a New Brunswick BioFlo310 bioreaction with a working volume of $1 \mathrm{~L}$. The reactor was set to a temperature of 30 degrees Celsius, an agitation of $1000 \mathrm{rpm}$, a pH of 8.8, and a gas flow rate of $100 \mathrm{sccm}$. The gas had concentrations of $2.5 \% \mathrm{CH}_{4}$ and $97.5 \%$ air; $10 \% \mathrm{CH}_{4}, 5 \% \mathrm{O}_{2}$, and $85 \% \mathrm{~N}_{2}$; or $20 \% \mathrm{CH}_{4}, 5 \%$ $\mathrm{O}_{2}$, and $75 \% \mathrm{~N}_{2}$ (depending on the experimental run). The biomass was collected and centrifuged at $5000 \mathrm{rpm}$ for $20 \mathrm{~min}$. A chloroform/methanol (2:1 v/v) solution was used to separate the lipids in the presence of tridecanoic acid. Fatty acids were then extracted with hexane. This experiment concluded that the case of methane-limitation results in the highest glycogen content.

Levett et al. [85] presented a design and study of a large-scale continuous bioreactor designed for methanotrophs for the production of polyhydroxyalkanoate (PHA) bioplastics. Though this design was focused on maximizing a bioplastic yield, the cultivation steps and subsequent extraction is very comparable to the steps required for the industrial process of obtaining biofuels from methanotrophic lipids. Levett et al. used a two-stage growth and accumulation technique on a mixed methanotrophic culture; a mixed culture was selected for their ability to self-regulate. Both steps of the bioreactor were operated at an elevated pressure ( 5 bar) to ensure that the methane is absorbed into the liquid biomass slurry. For the first step (growth and cultivation), the flue gas was set at $2 \%(v / v)$ methane, and the dilution rate was assumed to be $0.085 / \mathrm{h}$, which is considered by the authors as conservative. For the second step (accumulation), the biomass is semi-continuously harvested from the reactors for $24 \mathrm{~h}$ batch accumulations. Both air and methane are supplied in this phase with phosphorus being limited (this aids in the prevention of cell division, and methane is converted into $\mathrm{CO}_{2}$ and $\mathrm{PHB}$ ).

In an analysis performed by Chang and Alvarez-Choen in 1997 [86], they presented a two-stage methanotrophic bioreactor for the treatment of chlorinated wastewater. They used a dispersed-growth continuous flow stirred tank reactor (CFSTR) for the first step for the cultivation of methanotrophs in a $5 \mathrm{~L}$ system and a five-day detention time at a mixing rate of $500 \mathrm{rpm}$. This step operated at a temperature of 20 degrees Celsius in a copper-free environment. A mixture of $13 \%(v / v)$ methane to air was fed into the reactor at a rate of $12 \mathrm{~L} / \mathrm{h}\left(6 \% \mathrm{CO}_{2}, 7 \%\right.$ methane, and $\left.13 \% \mathrm{O}_{2}\right)$. The biomass yield for this reactor was $0.33 \mathrm{~g}$ of biomass per gram of methane used. The second stage mixed a trichloroethylene (TCE) stream of wastewater with a portion of the cell-rich effluent stream from step one in a flash mixer and then added to a treatment reactor with no head-space. Saturated TCE (1390 $\mathrm{mg} / \mathrm{L}$ ) was diluted with the water to produce the wastewater stream using syringe pumps. Sodium formate was added to the influent wastewater stream to reduce the energy limitations.

One interesting design for a methanotroph bioreactor was suggested by Steinberg et al. [87] and focuses on treating wastes anaerobically with methanotrophs for future space explorations. Their two-step system creates a high lipid containing biomass from human wastes. They suggested the first compartment to have a fixed-film, flow-through anaerobic digester to release methane and carbon 
dioxide. This methane would serve as the carbon source for the second reactor, which would contain methanotrophs. This reactor is fed oxygen for an aerobic process.

\section{Other Products from Methanotrophic Bacteria}

One method of improving both the economic and environmental impact of these systems is by integrating the process with other products; if both lipids and other coproducts were produced, the economic pressures of using this system will be reduced. Most of the useful products are found in the biomass after reaction, and processes similar to lipid extraction can be used to isolate these products $[19,44,81]$. The following section outlines three potential coproducts that could help marketability and economic feasibility.

Recent research has also suggested the use of methanotrophic bacteria for the production of putrescine, a chemical used in the industrial production of pharmaceuticals, surfactants, and agricultural chemicals. In an analysis by Nguyen and Lee, methanotrophs can be used efficiently as a source for putrescine. Their research concluded that the M. alcaliphilum 20ZE4-pACO strain produced up to 98.08 $\mathrm{mg} / \mathrm{L}$ [88]. Putrescine is also used often the plastics industry for substances such as nylon; it acts as the key structural unit for long polymer chains. The current process for creating putrescine is from the reaction between acrylonitrile and hydrogen cyanide [89]. The use of methanotrophs is a much more sustainable process that could offer a combined source for this chemical and others; this could be part of a system to maximize products from an environmentally favorable source.

Another potential byproduct of reactions by methanotrophic bacteria is ectoine. Ectoine is a useful compound in the pharmaceutical industry due to its ability to stabilize enzymes and nucleic acids. It is often found in the industrial production of skin care and sun protection products due to its ability to protect the skin from stress like UV radiation. Currently, the use of methanotrophs in this market is studied on M. alcaliphilum 20Z, which can contain up to $8 \%$ ectoine [74].

Methanotrophs also release methanol as a critical step in the conversion of methane [90]. Methanol serves an important building block in the industrial production of formaldehyde and acetic acid, both being important compounds across a wide scope of industries. Methanol directly holds an important place in industry as well. Due to its lower freezing point, it is used in antifreeze as a way to lower the freezing point of water; it is also used as an industrial solvent for products such as resins, dyes, and pharmaceutical products. However, its largest use is in the fuel industry, where it can be blended with gasoline to lower emissions [91].

A co-process integrating biofuels with any of these products would make this technique even more attractive for expanded use, further expanding its sustainability. The more products that can be sourced from methane, the more environmentally and economically friendly the process becomes.

\section{Challenges of Large-Scale Use of Methanotrophic Bacteria for Lipids and Other Products}

\subsection{Culturing}

As shown from the above cases, the use of methanotrophs for industrial products is feasible, but industrial-scale use requires more research and understanding of scaling-up methanotrophic processes. Though much work points towards the potential of these techniques, the lack of industrial examples and attempts of large-scale systems provides much unknown information about the viability of these systems in each of its major steps. One point of question is if the cultures used are representative of those in the environment, which oftentimes they are not; this is often a concern in the study of microorganisms and could cause issues in the large-scale use of these systems [19]. If the studies performed in the experimental designs lack proper representation to large-scale systems, unknown issues may possibly arise [19]. Along with this issue, there is great difficulty in the selection of the species of methanotroph; as explored earlier, there are many species of methanotrophs to select with multiple potential uses and risks $[19,46,92]$. For example, $M$. buryatense is commonly used experimentally for its ability to survive in a wide range of conditions and because it is easy to acquire $[1,26,93]$. Currently, however, it 
lacks enough lipid production for widespread use, requiring metabolic engineering research for better efficiency [26]. In addition, industrial scaling requires different conditions than experimental settings; one species of particular interest is Methylococcus capsulates because of its fast growth rate, genetic manipulation ability, and viability as one of the only methanotroph proven at an industrial scale [94]. However, there are still too few examples of large-scale use of methanotrophic bacteria to determine the optimal species.

\subsection{Medium Selection and Application}

In addition to the species, the selection and production of a usable medium must be performed in a cost-effective manner that ensure methanotrophic growth, a difficult goal considering the chemicals required (ammonium, copper source, etc.). As mentioned before, the medium usually contains the following chemicals: $\mathrm{MgSO} 4{ }^{*} 7 \mathrm{H}_{2} \mathrm{O}, \mathrm{CaCl}_{2}$, Sequestrene Iron Complex, and $\mathrm{NH}_{4} \mathrm{Cl}[49,88]$. More research and large-scale analyses need to be completed before the best mixture for industrial settings could be accurately determined, but there will definitely be issues in ensuring an economically viable solution. Mixing processes and reactor designs make industrial-scaling with medium use difficult. In addition to the medium, the reactor itself requires thorough analysis including stirring and gas supply costs, as well as construction and maintenance costs.

\subsection{Lipid-Extraction Methods}

Another potential problem is in the selection of an extraction method. Though hexane extraction seemed to prevail experimentally, there are concerns on its ability to be bought efficiently for its use in an industrial setting as it is very expensive [65]. Even though hexane extraction is most commonly used, the other methods discussed should also be considered (SFE, Bligh and Dyer, etc.). SFE is great at high level extraction but requires high temperatures and pressures, greatly elevating costs [78]. The Bligh and Dyer method should also be used carefully, as it is both toxic and costly $[76,80]$. These are just a few of the concerns that need to be addressed before the widespread use of the technology becomes feasible; however, this does not diminish the potential of this technology. There is still much promise for this process as hydrogen prices increase and environmental incentives spread.

\section{Summary}

The use of methanotrophic bacteria for biofuels is a promising source with potential to replace conventional fuel sources as a more sustainable, economical, and efficient method. These competitive costs offer a silver-lining in the future of the fuel industry to help minimize the release of dangerous greenhouse gases while providing a cost-effective source. The use of methanotrophs for biofuels would cut down on the emission of contaminants on two fronts, production and use. When methanotrophic bacteria are cultured, they intake a relatively large amount of methane from the atmosphere, and when they are used as a substitute for normal gasoline, they further reduce the overall release of greenhouse gasses. This two-faced source of lowering dangerous gasses in the atmosphere can play an integral role in protecting the environment. Though much more research and development are needed for large-scale applications of these systems, there is great hope in the future for these systems to be used commonly in industrial settings. There is much evidence to support the viability of this method. Bioreactor designs by Dong et al. and Gilman et al. show that large-scale production of biofuels from methanotrophs can be produced in high purities. As shown by Levett et al. and Chang and Alvarez-Choen, the resulting biomass from methanotrophic bacteria can easily be separated through long-standing and well-established methods. Additionally, Fei et al. reported that biofuels from methanotrophs have competitive costs. In addition to these encouraging reports, a co-process involving multiple products and multiple markets would further enhance the attractiveness of such a system.

Though there is some research in the large-scale application of methanotrophic bacteria in industry, much more needs to be done before widespread use of this technique become viable. There is little 
congruency of which methanotroph is best suited for large-scale production, and the methods of best extraction is not solidified. There are so many great sources of methane that are causing harm to the environment that could be converted as a source of fuel; however, without public support and academic advancement, little progress will be made on this front. More research and public awareness of this newly created advancement needs to be spread and improved upon before great change in the direction of the future of the planet can be achieved.

Author Contributions: Writing—original draft preparation and editing, A.Z.; Writing—review and editing, D.L.F. and W.E.H. All authors have read and agreed to the published version of the manuscript.

Funding: NASA EPSCoR (Agreement/Contract \#: 80NSSC18M0062).

Acknowledgments: The authors would like to acknowledge the financial support of the NASA EPSCoR (Agreement/Contract \#: 80NSSC18M0062), the Louisiana Board of Regents, and the UL Energy Institute of Louisiana. Appreciation is felt toward the faculty and staff of the Energy Institute of Louisiana for their review.

Conflicts of Interest: The authors declare no conflict of interest.

\section{References}

1. Gilman, A.; Laurens, L.M.; Puri, A.W.; Chu, F.; Pienkos, P.T.; Lidstrom, M.E.; Factories, M.C. Bioreactor performance parameters for an industrially-promising methanotroph Methylomicrobium buryatense 5GB1. Microb. Cell Fact. 2015, 14, 182. [CrossRef] [PubMed]

2. Henard, C.A.; Franklin, T.G.; Youhenna, B.; But, S.; Alexander, D.; Kalyuzhnaya, M.G.; Guarnieri, M.T. Biogas Biocatalysis: Methanotrophic Bacterial Cultivation, Metabolite Profiling, and Bioconversion to Lactic Acid. Front. Microbiol. 2018, 9, 2610. [CrossRef] [PubMed]

3. Ren, X.; Zhao, X.; Turcotte, F.; Deschênes, J.; Tremblay, R.; Jolicoeur, M. Current lipid extraction methods are significantly enhanced adding a water treatment step in Chlorella protothecoides. Microb. Cell Fact. 2017, 16, 26. [CrossRef] [PubMed]

4. Santos, A.L.; Preta, G. Lipids in the cell: Organisation regulates function. Cell. Mol. Life Sci. 2018, 75, 1909-1927. [CrossRef]

5. Cheng, M.H.; Rosentrater, K.A. Profitability analysis of soybean oil processes. Bioengineering 2017, 4, 83. [CrossRef]

6. Matthaus, B.; Özcan, M.M.; Juhaimi, F.A.l. Some rape/canola seed oils: Fatty acid composition and tocopherols. Z. Fur Nat.-Sect. C J. Biosci. 2016, 71, 73-77. [CrossRef]

7. Beef Tallow Price-Beef Tallow Price Manufacturers, Suppliers and Exporters on Alibaba.comAnimal Extract. Available online: https://www.alibaba.com/products/beef_tallow_price.html?IndexArea=product_ en (accessed on 12 July 2020).

8. List, G. Sunflower Seed and Oil. Lipid Technol. 2017, 29, 16. [CrossRef]

9. US Sunflower Oil Price. Available online: https://ycharts.com/indicators/us_sunflower_oil_price (accessed on 13 July 2020).

10. Yamada, M. Lipid Transfer Proteins in Plants and Microorganisms. Plant Cell Physiol. 1992, 33, 1-6. [CrossRef]

11. Roddy, D.J.; Sayigh, A. Comprehensive Renewable Energy; Elsevier: Amsterdam, The Netherlands, 2012.

12. Trabold, T.A.; Babbitt, C.W. Sustainable Food Waste-to-Energy Systems; Elsevier: Amsterdam, The Netherlands, 2018.

13. Hofstrand, D. Tracking Biodiesel Profitability. Available online: https://www.extension.iastate.edu/agdm/ energy/html/d1-15.html (accessed on 13 July 2020).

14. Monthly Diesel Fuel Retail Prices U.S. 2020|Statista. Available online: https://www.statista.com/statistics/ 204169/retail-prices-of-diesel-fuel-in-the-united-states-since-2009/ (accessed on 13 July 2020).

15. Dahiya, A. Cutting-edge Biofuel Conversion Technologies to Integrate into Petroleum-based Infrastructure and Integrated Biorefineries. In Bioenergy; Elsevier: Amsterdam, The Netherlands, 2015; pp. 467-485.

16. Rosen, M.J.; Kunjappu, J.T. Surfactants and Interfacial Phenomena; John Wiley \& Sons, Inc.: Hoboken, NJ, USA, 2012.

17. Surfactants Market Size Growth \& Share|Global Industry Report, 2022. Available online: https://www. grandviewresearch.com/industry-analysis/surfactants-market (accessed on 13 July 2020). 
18. Barnes, D.K.A.; Galgani, F.; Thompson, R.C.; Barlaz, M. Accumulation and fragmentation of plastic debris in global environments. Philos. Trans. R Soc. B Biol. Sci. 2009, 364, 1985-1998. [CrossRef]

19. Hanson, R.S.; Hanson, T.E. Methanotrophic bacteria. Microbiol. Rev. 1996, 60, 439-471. [CrossRef]

20. Iguchi, H.; Yurimoto, H.; Sakai, Y. Interactions of Methylotrophs with Plants and Other Heterotrophic Bacteria. Microorganisms 2015, 3, 137-151. [CrossRef] [PubMed]

21. Smith, T.J.; Murrell, J.C. Methanotrophy/methane oxidation. In Encyclopedia of Microbiology; Elsevier Inc.: Amsterdam, The Netherlands, 2009; pp. 293-298.

22. Anthony, C.; York Paris, N.; Diego, S.; Francisco, S. The Biochemistry of Methylotrophs; Academic Press: London, UK; New York, NY, USA, 1982.

23. Jiang, H.; Chen, Y.; Jiang, P.; Zhang, C.; Smith, T.J.; ColinMurrell, J.; Xing, X.-H. Methanotrophs: Multifunctional bacteria with promising applications in environmental bioengineering. Biochem. Eng. J. 2010, 49, 277-288. [CrossRef]

24. Canfield, D.E.; Kristensen, E.; Thamdrup, B. Aquatic geomicrobiology (1st edition). Adv. Mar. Biol. 2005.

25. Aimen, H.; Khan, A.S.; Kanwal, N. Methanotrophs: The Natural Way to Tackle Greenhouse Effect. J. Bioremediat. Biodegrad. 2018, 9. [CrossRef]

26. Donga, T.; Fei, Q.; Genelot, M.; Smith, H.; Laurens, L.M.L.; Watson, M.J.; Pienkos, P.T. A novel integrated biorefinery process for diesel fuel blendstock production using lipids from the methanotroph, Methylomicrobium buryatense. Energy Convers. Manag. 2017, 140, 62-70. [CrossRef]

27. Messerschmidt, A. Enzymes and Enzyme Mechanisms. Compr. Nat. Prod. II (1st Edition) 2010.

28. Theisen, A.R.; Murrell, J.C. Facultative methanotrophs revisited. J. Bacteriol. 2005, 187, 4303-4305. [CrossRef]

29. Ross, M.O.; Rosenzweig, A.C. A tale of two methane monooxygenases. J. Biol. Inorg. Chem. 2017, 22, 307-319. [CrossRef]

30. Castresana, J.; Lübben, M.; Saraste, M.; Higgins, D.G. Evolution of cytochrome oxidase, an enzyme older than atmospheric oxygen. EMBO J. 1994, 13, 2516-2525. [CrossRef]

31. Rasigraf, O.; Kool, D.M.; Jetten, M.S.M.; Damsté, J.S.S.; Ettwig, K.F. Autotrophic carbon dioxide fixation via the Calvin-Benson-Bassham cycle by the denitrifying methanotroph "Candidatus Methylomirabilis oxyfera". Appl. Environ. Microbiol. 2014, 80, 2451-2460. [CrossRef]

32. Greenhouse Gas Inventory|California Air Resources Board. Available online: https://www2.arb.ca.gov/ourwork/programs/greenhouse-gas-inventory (accessed on 12 July 2020).

33. Overview of Greenhouse Gases|Greenhouse Gas (GHG) Emissions|US EPA. Available online: https://www. epa.gov/ghgemissions/overview-greenhouse-gases (accessed on 13 July 2020).

34. Pandey, V.C.; Singh, J.S.; Singh, D.P.; Singh, R.P. Methanotrophs: Promising bacteria for environmental remediation. Int. J. Environ. Sci. Technol. 2014, 11, 241-250. [CrossRef]

35. Singh, J.S.; Singh, D.P. Methanotrophs: An emerging bioremediation tool with unique broad spectrum methane monooxygenase (MMO) enzyme. In Agro-Environmental Sustainability; Springer International Publishing: Berlin/Heidelberg, Germany, 2017; pp. 1-18.

36. Semrau, J.D. Bioremediation via methanotrophy: Overview of recent findings and suggestions for future research. Front. Microbiol. 2011, 2, 209. [CrossRef] [PubMed]

37. US EPA O Basic Information about Landfill Gas. Available online: https://www.epa.gov/lmop/basicinformation-about-landfill-gas (accessed on 25 June 2020).

38. Cébron, A.; Bodrossy, L.; Chen, Y.; Singer, A.C.; Thompson, I.P.; Prosser, J.I.; Murrell, J.C. Identity of active methanotrophs in landfill cover soil as revealed by DNA-stable isotope probing. FEMS Microbiol. Ecol. 2007, 62, 12-23. [CrossRef]

39. Fu, Y.; Li, Y.; Lidstrom, M. The oxidative TCA cycle operates during methanotrophic growth of the Type I methanotroph Methylomicrobium buryatense 5GB1. Metab. Eng. 2017, 42, 43-51. [CrossRef] [PubMed]

40. Puri, A.W.; Owen, S.; Chu, F.; Chavkin, T.; Beck, D.A.C.; Kalyuzhnaya, M.G.; Lidstrom, M.E. Genetic tools for the industrially promising methanotroph Methylomicrobium buryatense. Appl. Environ. Microbiol. 2015, 81, 1775-1781. [CrossRef]

41. Karlsen, O.A.; Berven, F.S.; Jensen, H.B.; Fjellbirkeland, A. Methods in Methane Metabolism, Part B: Methanotrophy; Elsevier: Amsterdam, The Netherlands, 2011.

42. Tikhonova, E.N.; Kravchenko, I.K. Activity and diversity of aerobic methanotrophs in thermal springs of the russian far east. In New and Future Developments in Microbial Biotechnology and Bioengineering: Microbial Biotechnology in Agro-Environmental Sustainability; Elsevier: Amsterdam, The Netherlands, 2019; pp. 1-30. 
43. Wang, F.; Zhang, Y.; Chen, Y.; He, Y.; Qi, J.; Hinrichs, K.; Zhang, X.; Xiao, X.; Boon, N. Methanotrophic archaea possessing diverging methane-oxidizing and electron-Transporting pathways. ISME J. 2014, 8, 1069-1078. [CrossRef]

44. Cassarini, C.; Zhang, Y.; Lens, P.N.L. Pressure Selects Dominant Anaerobic Methanotrophic Phylotype and Sulfate Reducing Bacteria in Coastal Marine Lake Grevelingen Sediment. Front. Environ. Sci. 2019, 6, 162. [CrossRef]

45. Timmers, P.H.A.; Welte, C.U.; Koehorst, J.J.; Plugge, C.M.; Jetten, M.S.M.; Stams, A.J.M. Reverse Methanogenesis and Respiration in Methanotrophic Archaea. Archaea 2017, 2017. [CrossRef]

46. Knittel, K.; Lösekann, T.; Boetius, A.; Kort, R.; Amann, R. Diversity and distribution of methanotrophic archaea at cold seeps. Appl. Environ. Microbiol. 2005, 71, 467-479. [CrossRef]

47. Fradet, D.T.; Tavormina, P.L.; Orphan, V.J. Members of the methanotrophic genus Methylomarinum inhabit inland mud pots. PeerJ 2016, 4, e2116. [CrossRef]

48. Burdette, M. Production of Biodiesel-Like Components by the Type I Methanotroph Methylomonas Methanica. Master's Thesis, Clemson University, Clemson, SC, USA, August 2013.

49. Sundstrom, E.R.; Criddle, C.S. Optimization of methanotrophic growth and production of poly(3-hydroxybutyrate) in a high-throughput microbioreactor system. Appl. Environ. Microbiol. 2015, 81, 4767-4773. [CrossRef] [PubMed]

50. Bussmann, I.; Rahalkar, M.; Schink, B. Cultivation of methanotrophic bacteria in opposing gradients of methane and oxygen. FEMS Microbiol. Ecol. 2006, 56, 331-344. [CrossRef] [PubMed]

51. Farhan Ul Haque, M.; Crombie, A.T.; Ensminger, S.A.; Baciu, C.; Murrell, J.C. Facultative methanotrophs are abundant at terrestrial natural gas seeps. Microbiome 2018, 6, 118. [CrossRef]

52. Kolb, S.; Knief, C.; Stubner, S.; Conrad, R. Quantitative detection of methanotrophs in soil by novel pmoA-targeted real-time PCR Assays. Appl. Environ. Microbiol. 2003, 69, 2423-2429. [CrossRef] [PubMed]

53. Skennerton, C.T.; Ward, L.M.; Michel, A.; Metcalfe, K.; Valiente, C.; Mullin, S.; Chan, K.Y.; Gradinaru, V.; Orphan, V.J. Genomic Reconstruction of an Uncultured Hydrothermal Vent Gammaproteobacterial Methanotroph (Family Methylothermaceae) Indicates Multiple Adaptations to Oxygen Limitation. Front. Microbiol. 2015, 6, 1425. [CrossRef]

54. Merkel, A.Y.; Huber, J.A.; Chernyh, N.A.; Bonch-Osmolovskaya, E.A.; Lebedinsky, A.V. Detection of putatively thermophilic anaerobic methanotrophs in diffuse hydrothermal vent fluids. Appl. Environ. Microbiol. 2013, 79, 915-923. [CrossRef]

55. Singleton, M.; McCalley, C.K.; Woodcroft, B.J.; Boyd, J.A.; Evans, P.N.; Hodgkins, S.B.; Chanton, J.P.; Frolking, S.; Crill, P.M.; Saleska, S.R. Methanotrophy across a natural permafrost thaw environment. ISME J. 2018, 12, 2544-2558. [CrossRef]

56. Crevecoeur, S.; Vincent, W.F.; Comte, J.; Matveev, A.; Lovejoy, C. Diversity and potential activity of methanotrophs in high methane-emitting permafrost thaw ponds. PLoS ONE 2017, 12, e0188223. [CrossRef]

57. General Culturing Tips|Methanotroph Commons. Available online: http://www.methanotroph.org/wiki/ culturing-tips/ (accessed on 12 July 2020).

58. Akberdin, I.R.; Thompson, M.; Hamilton, R.; Desai, N.; Alexander, D.; Henard, C.A.; Guarnieri, M.T.; Kalyuzhnaya, M.G. Methane utilization in Methylomicrobium alcaliphilum 20ZR: A systems approach. Sci. Rep. 2018, 8, 2512. [CrossRef]

59. Tays, C.; Guarnieri, M.T.; Sauvageau, D.; Stein, L.Y. Combined Effects of Carbon and Nitrogen Source to Optimize Growth of Proteobacterial Methanotrophs. Front. Microbiol. 2018, 9, 2239. [CrossRef]

60. Kuźniar, A.; Furtak, K.; Włodarczyk, K.; Stępniewska, Z.; Wolińska, A. Methanotrophic bacterial biomass as potential mineral feed ingredients for animals. Int. J. Environ. Res. Public Health 2019, 16, 2674. [CrossRef]

61. Roell, G.W.; Zha, J.; Carr, R.R.; Koffas, M.A.; Fong, S.S.; Tang, Y.J. Engineering microbial consortia by division of labor. Microb. Cell Fact. 2019, 18, 35. [CrossRef] [PubMed]

62. Jawed, K.; Yazdani, S.S.; Koffas, M.A. Advances in the development and application of microbial consortia for metabolic engineering. Metab. Eng. Commun. 2019, 9, e00095. [CrossRef] [PubMed]

63. Yalkowsky, S.H.; He, Y.; Jain, P. Handbook of Aqueous Solubility Data; CRC Press: Boca Raton, FL, USA, 2016.

64. Chemical Composition of Natural Gas - Union Gas. Available online: https://www.uniongas.com/about-us/ about-natural-gas/chemical-composition-of-natural-gas (accessed on 12 July 2020).

65. Fei, Q.; Guarnieri, M.T.; Tao, L.; Laurens, L.M.L.; Dowe, N.; Pienkos, P.T. Bioconversion of natural gas to liquid fuel: Opportunities and challenges. Biotechnol. Adv. 2014, 32, 596-614. [CrossRef] 
66. Just The Facts - Average Price of Natural Gas - The Public Policy Institute. Available online: http: //www.ppinys.org/reports/jtf2004/naturalgas.htm (accessed on 12 July 2020).

67. What is Renewable Natural Gas?|SoCalGas. Available online: https://www.socalgas.com/smart-energy/ renewable-gas/what-is-renewable-natural-gas (accessed on 13 July 2020).

68. Parker, N.; Williams, R.; Dominguez-Faus, R.; Scheitrum, D. Renewable natural gas in California: An assessment of the technical and economic potential. Energy Policy 2017, 111, 235-245. [CrossRef]

69. Renewable Natural Gas Rates. Available online: https://www.fortisbc.com/services/sustainable-energyoptions/renewable-natural-gas/renewable-natural-gas-rates (accessed on 13 July 2020).

70. Whittenbury, R.; Phillips, K.C.; Wilkinson, J.F. Enrichment, isolation and some properties of methane-utilizing bacteria. J. Gen. Microbiol. 1970, 61, 205-218. [CrossRef]

71. Karthikeyan, O.P.; Saravanan, N.; Cirés, S.; Alvarez-Roa, C.; Razaghi, A.; Chidambarampadmavathy, K.; Velu, C.; Subashchandrabose, G.; Heimann, K. Culture scale-up and immobilisation of a mixed methanotrophic consortium for methane remediation in pilot-scale bio-filters. Environ. Technol. (U. K.) 2017, 38, 474-482. [CrossRef]

72. Hoefman, S.; van der Ha, D.; de Vos, P.; Boon, N.; Heylen, K. Miniaturized extinction culturing is the preferred strategy for rapid isolation of fast-growing methane-oxidizing bacteria. Microb. Biotechnol. 2012, 5, 368-378. [CrossRef]

73. Prabandono, K.; Amin, S. Biofuel Production from Microalgae. In Handbook of Marine Microalgae, Biotechnology Advances; Elsevier Inc.: Amsterdam, The Netherlands, 2015; pp. 145-158.

74. Lee, E.Y. METHANOTROPHS: Microbiology fundamentals and biotechnological applications. Springer Nat. 2019, 1, 163-203.

75. Jahnke, L.L.; Summons, R.E.; Hope, J.M.; Des Marais, D.J. Carbon isotopic fractionation in lipids from methanotrophic bacteria II: The effects of physiology and environmental parameters on the biosynthesis and isotopic signatures of biomarkers. Geochim. Cosmochim. Acta 1999, 63, 79-93. [CrossRef]

76. Bligh, E.G.; Dyer, W.J. A rapid method of total lipid extraction and purification. Can. J. Biochem. Physiol. 1959, 37, 911-917. [CrossRef] [PubMed]

77. Shin, H.; Shim, S.; Ryu, Y.; Yang, J.; Lim, S.; Lee, C. Lipid Extraction from Tetraselmis sp. Microalgae for Biodiesel Production Using Hexane-based Solvent Mixtures. Biotechnol. Bioprocess. Eng. 2018, 23, 16-22. [CrossRef]

78. Supercritical Fluid Extraction (SFE) Systems: Waters. Available online: https://www.waters.com/ waters/en_US/Supercritical-Fluid-Extraction-(SFE)-Systems/nav.htm?cid=10146521\&locale=en_US (accessed on 13 July 2020).

79. Chester, T.L.; Pinkston, J.D.; Raynie, D.E. Supercritical Fluid Chromatography/Mass Spectrometry. In Practical Supercritical Fluid Chromatography and Extraction; American Chemical Society: Washington, DC, USA, 2018; pp. 161-178.

80. Breil, C.; Vian, M.A.; Zemb, T.; Kunz, W.; Chemat, F. "Bligh and Dyer" and Folch methods for solid-liquid-liquid extraction of lipids from microorganisms. Comprehension of solvatation mechanisms and towards substitution with alternative solvents. Int. J. Mol. Sci. 2017, 18, 708. [CrossRef]

81. Gorgich, M.; Mata, T.M.; Martins, A.A.; Branco-Vieira, M.; Caetano, N.S. Comparison of different lipid extraction procedures applied to three microalgal species. In Energy Reports; Elsevier Ltd.: Amsterdam, The Netherlands, 2020; pp. 477-482.

82. Kwangdinata, R.; Raya, I.; Zakir, M. Production of Biodiesel from Lipid of Porphyridium cruentum through Ultrasonic Method. IRSN Renew. Energy 2014, 2014, 107278. [CrossRef]

83. Transesterification to Biodiesel. Available online: https://www.etipbioenergy.eu/value-chains/conversiontechnologies/conventional-technologies/transesterification-to-biodiesel (accessed on 13 July 2020).

84. Raut, G.; Kamat, S.; Ravikumar, A. Trends in production and fuel properties of biodiesel from heterotrophic microbes. In Advances in Biological Science Research: A Practical Approach; Elsevier: Amsterdam, The Netherlands, 2019; pp. 247-273.

85. Levett, I.; Birkett, G.; Davies, N.; Bell, A.; Langford, A.; Laycock, B.; Lant, P.; Pratt, S. Techno-economic assessment of poly-3-hydroxybutyrate (PHB) production from methane - The case for thermophilic bioprocessing. J. Environ. Chem. Eng. 2016, 4, 3724-3733. [CrossRef]

86. Chang, H.L.; Alvarez-Cohen, L. Two-stage methanotrophic bioreactor for the treatment of chlorinated organic wastewater. Water Res. 1997, 31, 2026-2036. [CrossRef] 
87. Steinberg, L.M.; Kronyak, R.E.; House, C.H. Coupling of anaerobic waste treatment to produce protein- and lipid-rich bacterial biomass. Life Sci. Space Res. 2017, 15, 32-42. [CrossRef]

88. Nguyen, L.T.; Lee, E.Y. Biological conversion of methane to putrescine using genome-scale model-guided metabolic engineering of a methanotrophic bacterium Methylomicrobium alcaliphilum 20Z. Biotechnol. Biofuels 2019, 12, 147. [CrossRef]

89. Broadwith, P. Magnificent Molecules (Putrescine and Cadaverine), 2012. Royal Society of Chemistry. Available online: http://www.rsc.org/images/TM0512-putrescine-cadaverine_tcm18-221656.pdf (accessed on 30 July 2020).

90. Strong, P.J.; Xie, S.; Clarke, W.P. Methane as a resource: Can the methanotrophs add value? Environ. Sci. Technol. 2015, 49, 4001-4018. [CrossRef]

91. Chemical Safety Facts About Methanol. Available online: https://www.chemicalsafetyfacts.org/methanol/ (accessed on 13 July 2020).

92. Knief, C. Diversity and habitat preferences of cultivated and uncultivated aerobic methanotrophic bacteria evaluated based on pmoA as molecular marker. Front. Microbiol. 2015, 6, 1346. [CrossRef]

93. Fu, S.; Xu, X.; Dai, M.; Yuan, X.; Guo, R. Hydrogen and methane production from vinasse using two-stage anaerobic digestion. Process. Saf. Environ. Prot. 2017, 107, 81-86. [CrossRef]

94. Calysta. Producing Protein and Plastics from Methane, a Sustainable Platform for Biotechnology, 2017. Bio.org. Available online: https:/www.bio.org/sites/default/files/0830AM-Lori\%20Giver.pdf (accessed on 30 July 2020).

(C) 2020 by the authors. Licensee MDPI, Basel, Switzerland. This article is an open access article distributed under the terms and conditions of the Creative Commons Attribution (CC BY) license (http://creativecommons.org/licenses/by/4.0/). 